M.J. Douglas MD FRCP, J.H.K. Kim MD FRCP, P.L.E. Ross MD BSC (Meds) FRCP, G.H. McMorland MB CHB FRCP

\title{
The effect of epinephrine in local anaesthetic on epidural morphine- induced pruritus
}

The severity of epidural morphine-induced pruritus was evaluated following the addition of epinephrine to the local anaesthetic solution used for Caesarean section anaesthesia. The local anaesthetic solutions used were: Group I - 0.5 per cent bupivacaine plain -20 patients. Group II - 0.5 per cent bupivacaine with 1:400,000 epinephrine - 25 patients. Group III -0.5 per cent bupivacaine with 1:200,000 epinephrine for the $3 \mathrm{ml}$ "test dose" followed by 0.5 per cent bupivacaine plain for anaesthesia- 21 patients.

The severity of the pruritus, as measured by completion of a visual analogue "itch scale" and by requests for medication for pruritus, was statistically significantly greater in both groups in which epinephrine was added. This effect was not dose-related, as the "test dose" group (15 $\mu \mathrm{g}$ epinephrine) experienced the most severe itch. This tatter difference was also statistically significant $(p<0.05)$.

\section{Key words}

OBSTETRICAL ANAESTHESIA: epidural; ANALGESIA: epidural morphine; SYMPATHETIC NERVOUS SYSTEM, CATECHOLAMINES: epinephrine.

From the Department of Anaesthesia, University of British Columbia and Grace Hospital, Vancouver, B.C. Address correspondence to: Dr. M.J. Douglas, Department of Anaesthesia. Grace Hospital, 4490 Oak Street, Vancouver, B.C. V6H 3 V5.
Bromage has reported that cutaneous hypalgesia was more intense, faster in onset and longer in duration after the epidural injection of an epinephrine-morphine mixture, than after plain epidural morphine.' Side effects of pruritus, nausea, vomiting and difficulty of micturition were also more intense after the epinephrine-morphine combination. The effects of epidural ephinephrine $(50 \mu \mathrm{g})$ alone were also studied and it was found that objective signs of limited, segmental hypalgesia developed 20 minutes after injection and that this effect lasted six hours.

This study was undertaken to evaluate prospectively the effect of epinephrine, as an adjuvant to the local anaesthetic for Caesarean section, on the incidence and severity of pruritus occurring after epidural morphine administration.

\section{Methods}

Following institutional approval, 66 patients, ASA physical status I or II, scheduled for elective Caesarean section were entered into the study. Informed consent was obtained from each patient.

Following placement of an indwelling epidural catheter at either $\mathrm{L}_{2-3}$ or $\mathrm{L}_{3-4}$, one of three local anaesthetic solutions was injected through the catheter to achieve a sensory level of $T_{3}$ or $T_{4}$.

The patients were randomly allocated to the three groups according to a previously determined schedule. Group I received 0.5 percent bupivacaine plain for a $3 \mathrm{ml}$ test dose and anaesthesia. Group II received 0.5 per cent bupivacaine with freshly added epinephrine to a concentration of 1:400,000, for the $3 \mathrm{ml}$ test dose and anaesthesia. Group III received 0.5 per cent bupivacaine with 1:200,000 epinephrine (freshly added), for the $3 \mathrm{ml}$ test dose 
TABLE I Comparison of the three groups with respect to amount of epinephrine, volume of local anaesthetic and incidence of pruritus

\begin{tabular}{llll}
\hline Number & $\begin{array}{l}\text { Group I } \\
20\end{array}$ & $\begin{array}{l}\text { Group II } \\
25\end{array}$ & $\begin{array}{l}\text { Group III } \\
2 I\end{array}$ \\
\hline Total amount of epinephrine added $(\mu \mathrm{g})$ & 0 & $45 \pm 3.2$ & 15 (test dose) \\
Volume of local anaesthetic $(\mathrm{ml})$ & $20.3 \pm 2.6^{\dagger}$ & $18 \pm 1.3$ & $18.5 \pm 1.2$ \\
Incidence of pruritus* & $65 \%$ & $75 \%$ & $100 \%$ \\
\hline
\end{tabular}

All values are mean $\pm S$.E.

* See text for criteria for determining incidence.

$\mathrm{tp}<0.05$

followed by 0.5 per cent bupivacaine plain for anaesthesia.

Blood pressure, and ECG were monitored throughout the procedure and the patients received oxygen by face mask until the baby was born. Twenty minutes after delivery, each patient was given $5 \mathrm{mg}$ preservative-free morphine in $10 \mathrm{ml}$ of 0.9 per cent saline through the epidural catheter. At the end of the procedure, the epidural catheter was removed and the patient was transferred to the recovery room.

Each patient was given a visual analogue "itch scale" $(0-10 \mathrm{~cm})$ to complete when itching "became bothersome" or six hours after administration of the epidural morphine. The chart of each patient was reviewed to determine if any medication had been given for pruritus. Neither the nursing staff nor the patients were aware of the local anaesthetic solution used.

Data were analyzed for statistical significance using Student's t test, the Mann-Whitney U test and chi square analysis, where indicated. A p value less than 0.05 was considered statistically significant.

\section{Results}

Sixty-six patients were studied. There were 20 patients in Group I, 25 in Group II and 21 in Group III. The patient populations in the three groups were similar in respect to age, height, and weight. The volume of the local anaesthetic used for Group $I$ was slightly greater than that for the groups containing epinephrine $-20.3 \pm 2.6 \mathrm{ml}$, versus $18.0 \pm 1.3 \mathrm{ml}$ for Group II and $18.5 \pm 1.2 \mathrm{ml}$ for Group III. The amount of epinephrine in Group II was $45.1 \pm$ $3: 2 \mu \mathrm{g}$ (mean \pm S.E.) (Table I).

If one assumes that a value of less than two on the visual analogue scale is associated with very mild pruritus - such that one has to ask about it to elicit the information, then one can use a value of greater than two as a measure of incidence of pruritus. Group I had an incidence of 65 per cent, group II an incidence of 76 per cent and group III an incidence of 100 per cent (Table I).

The mean scores of the severity of the pruritus (as measured on the visual analogue scale) were $2.6 \pm$ 0.4 for Group I, $4.5 \pm 0.7$ for Group II and $6.4 \pm$ 0.5 for Group III. Using the Mann-Whitney U test the differences between Groups I and II, I and III and II and III were all statistically significant, $\mathrm{p}<$ 0.05 (Table II).

The number of patients who received medication (benadryl and/or naloxone) for pruritus was 5 in Group I, 15 in Group II and 11 in Group III (Table III). Using chi square analysis the difference between the groups is statistically significant $p<$ 0.01 . There were two patients in Group I with pruritus scores greater than five and 0 patients with scores greater than eight, while in Group II, there were 13 with a score greater than five and four with a score greater than eight and Group III contained 16 patients with scores greater than five and seven patients with scores greater than eight. These results also differ significantly (Table III).

TABLE II Comparison of severity of pruritus as determined by the "itch scale"

\begin{tabular}{ll}
\hline & Itch scale measurement \\
\hline Group I & $2.6 \pm 0.4$ \\
Group II & $4.5 \pm 0.7^{*}$ \\
Group III & $6.4 \pm 0.5^{* \dagger}$ \\
\hline
\end{tabular}

All values are mean \pm S.E.M.

$*_{p}<0.05$ compared with Group I.

$\dagger<0.05$ compared with Group II. 
TABLE III Comparison of the severity of pruritus as determined by receipt of medication for pruritus and of "itch scale" measurement greater than 5 and greater than 8

\begin{tabular}{llll}
\hline & $\begin{array}{l}\text { Group I } \\
\text { number (\%) }\end{array}$ & $\begin{array}{l}\text { Group II } \\
\text { number (\%) }\end{array}$ & $\begin{array}{l}\text { Group III } \\
\text { number (\%) }\end{array}$ \\
\hline Received medication for pruritus & $5(25)$ & $15(60)$ & $11(52)^{*}$ \\
Itch scale $>5$ & $2(10)$ & $13(52)$ & $16(76) \dagger$ \\
Itch scale $>8$ & $0(0)$ & $4(16)$ & $7(33) \ddagger$ \\
\hline
\end{tabular}

$*_{p}<0.01$

$t_{\mathrm{p}}<0.001$.

$\ddagger \mathrm{p}<0,02$.

\section{Discussion}

In 1983 Bromage demonstrated that segmental hypalgesia occurred after injection of epinephrine in saline into the epidural space and that this effect lasted six hours. No adverse effects, such as pruritus, were found. As well, in volunteers he demonstrated that epinephrine added to epidural morphine enhanced the severity of all the sideeffects of epidural morphine, including depression of respiratory sensitivity to carbon dioxide. ${ }^{1}$ These findings were confirmed by Collier. ${ }^{2}$ To date, there has not been a study to examine the effects of epinephrine added to the local anaesthetic, at the time of anaesthesia, on the side-effects of epidural morphine, administered later.

The side-effect of epidural morphine which is easiest to measure, albeit subjectively, is pruritus. Pruritus generally appears approximately $3.0 \pm$ 0.33 hours and lasts for $5.5 \pm 4$ hours after injection of epidural morphine. ${ }^{3}$ By selecting a time of six hours after administration of epidural morphine or when "itching became bothersome" for the completion of the visual analogue "itch scale," it was felt that this would provide a fairly accurate representation of the severity of the patient's pruritus. Although the measurement is subjective, one would expect patients in all groups to be equivalent in their perceptions of the degree of pruritus.

The incidence of pruritus which was noted for Groups I and II compares with that shown in several studies. ${ }^{4-6}$ The 100 per cent incidence in group III (the "test dose" group) is comparable to Bromage's study in volunteers where he found that epinephrine added to epidural morphine resulted in a 100 per cent incidence of pruritus. He used a $10 \mathrm{mg}$ dose of morphine, in contrast to the $5 \mathrm{mg}$ used in this study. ${ }^{1}$

Epinephrine was freshly added to each of the solutions used. This was done to rule out the effect of $\mathrm{pH}$ change. Commercial preparations of epinephrine-containing local anaesthetic solutions have a lower $\mathrm{pH}$ than non-epinephrine containing solutions. The $\mathrm{pH}$ of plain 0.5 per cent bupivacaine is 5.37 while that of bupivacaine with $1: 200,000$ epinephrine is $3.80 .^{7}$ As the authors are unaware of the effect of $\mathrm{pH}$ change on the action of epinephrine in the epidural space, it was decided to maintain a constant $\mathrm{pH}$ of bupivacaine in this study.

This study has demonstrated that the addition of epinephrine to the local anaesthetic still exerts an enhancing effect on epidural morphine-induced pruritus, even though 45-65 minutes had elapsed since the administration of the epinephrine. As Bromage demonstrated that the effect of epinephrine alone lasted six hours, this should not be surprising. 1

One of the more interesting findings from this study is that the enhancement of the pruritus does not appear to be dose-related, in that the $15 \mu \mathrm{g}$ epinephrine (test dose) exerted a slightly greater effect than the larger dose of epinephrine (45.1 \pm $3.2 \mu \mathrm{g}$ ). This may imply that the initial amount of epinephrine injected into the epidural space may be the critical factor in determining the overall response.

This study has shown an enhancement of epidural morphine induced pruritus by the addition of epinephrine to the local anaesthetic. As volunteer studies $^{1,2}$ have shown that all of the side effects of epidural morphine are enhanced by the addition of epinephrine to the morphine, the side effects of nausea, vomiting, urinary retention and respiratory depression might also be increased when epinephrine is added to the local anaesthetic. Clinically, this may be important in relation to the risk of respiratory depression. This study did not examine 
the other side-effects and this is an area which needs to be addressed.

With the increased emphasis on the use of an epinephrine-containing test dose, the findings of this study need to be considered. It may be possible to have the same degree of analgesia from a lower dose of epidural morphine. Bromage demonstrated better and longer lasting analgesia when epinephrine was added to epidural morphine. A doubleblind study, comparing the analgesia and side effects of lower doses of epidural morphine following local anaesthesia with plain and epinephrinecontaining solutions, needs to be done.

\section{Conclusion}

This study has demonstrated that the addition of epinephrine to the local anaesthetic used for Caesarean section anaesthesia increases the severity of the epidural morphine-induced pruritus. The possibility that other side effects might also be enhanced needs to be addressed. More information is required on the pharmacokinetics of epinephrine in the epidural space.

\section{References}

1 Bromage PR, Camporesi EM, Durant PAC, Nielsen $\mathrm{CH}$. Influence of epinephrine as an adjuvant to epidural morphine. Anesthesiology 1983; 58: 257-62.

2 Collier $C$. Epinephrine and epidural narcotics. Letter. Anesthesiology 1984; 60: 168.

3 Bromage PR, Camporesi EM, Durant PAC, Nielsen $\mathrm{CH}$. Nonrespiratory side effects of epidural morphine. Anesth Analg 1982; 61: 490-5.

4 Carmichael FJ, Rolbin SH, Hew EM. Epidural morphine for analgesia after Caesarean section. Can Anaesth Soc J 1982; 29: 359-63.

5 Bromage PR, Camporesi EM, Durant AC, Nielsen $C H$. Rostral spread of epidural morphine. Anesthesiology 1982; 56: 431-6.

6 Torda TA, Pybus DA, Liberman H, Clark $M$, Crawford $M$. Experimental comparison of extradural and I.M. morphine. Br J Anaesth 1980; 52: 939-42.

7 Moore $D C$. The $\mathrm{pH}$ of local anesthetic solutions. Anesth Analg 1981; 60: 833-4.

\section{Résumé}

La sévérité du prurit induit par l'injection épidurale de morphine a été évaluée suite à l' addition de l'épinéphrine à l'anesthésique local lors de l'anesthésie pour césarienne. Les solutions d' anesthésiques locaux utilisées étaient: 1) 0.5 pour cent bupivacaine - 20 patients; 2) 0.5 pour cent bupivacaine avec 1:400,000 d'éphinéphrine - 25 patients; 3) 0.5 pour cent bupivacaine avec 1:200,000 épinéphrine pour $3 \mathrm{ml}$ "test dose" suivi de 0.5 pour cent bupivacaine simple - 21 patients. La sévérité du prurit, telle que mesurée par un test visuel "itch scale" et par la demande de médicaments contre le prurit était statis. tiquement significative et plus grande dans les deux groupes où l'épinéphrine était ajoutée. Cet effet n'était pas dépendant de la dose, car le groupe qui a reçu une dose test (15 $\mu g$ d'épinéphrine) a éprouvé le prurit le plus sévère. Cette dernière était aussi statistiquement significative $(p<0.05)$. 